\title{
Mindfulness and Aerobic Exercise as an Intervention for Cognitive Dysfunction Following an Acquired Brain Injury: A Pilot Study
}

\author{
Lovisa Hellgren 1,2*, Anna Lundqvist ${ }^{2,3}$, Björn Börsbo ${ }^{1,2}$, Richard Levi ${ }^{2,3}$, Kersti Samuelsson ${ }^{2,3}$ \\ ${ }^{1}$ Department of Rehabilitation Medicine, Region Jönköping County, Jönköping, Sweden \\ ${ }^{2}$ Department of Medical and Health Sciences, Linköping University, Linköping, Sweden \\ ${ }^{3}$ Department of Rehabilitation Medicine, Linköping University, Linköping, Sweden \\ Email: *lovisa.hellgren@liu.se
}

How to cite this paper: Hellgren, L., Lundqvist, A., Börsbo, B., Levi, R. and Samuelsson, K. (2019) Mindfulness and Aerobic Exercise as an Intervention for Cognitive Dysfunction Following an Acquired Brain Injury: A Pilot Study. Open Journal of Therapy and Rehabilitation, 7 , $12-24$.

https://doi.org/10.4236/ojtr.2019.71002

Received: January 27, 2019

Accepted: February 24, 2019

Published: February 27, 2019

Copyright $\odot 2019$ by author(s) and Scientific Research Publishing Inc. This work is licensed under the Creative Commons Attribution International License (CC BY 4.0).

http://creativecommons.org/licenses/by/4.0/

\section{(c) (i) Open Access}

\begin{abstract}
Background: Cognitive impairments as sequelae of brain injury are common and can negatively affect activities of everyday life, participation and quality of life. Thus, finding ways to reduce cognitive impairments and ameliorate their negative impact on everyday life is an important focus of research. Aim: The aim of this pilot study was to analyse the effects of a combination of guided mindfulness and aerobic exercise on cognitive ability and mental fatigue in patients with acquired brain injury (ABI). Design: Pilot study, with a before-after design. Setting: Outpatient. Population: Twenty-one patients suffering from ABI, former patients of three rehabilitation medicine departments. Methods: The intervention comprised a structured combination of guided mindfulness program and outdoor walking, three times/week for 12 weeks. The outcome measures included assessment of information processing speed, working memory, oxygen uptake and self-reported mental fatigue. Results: The main results showed improvements in cognitive abilities related to information processing speed, perceived mental fatigue and physical capacity. Conclusions: A combination of mindfulness and physical activity can increase information processing speed and ameliorate mental fatigue. Further studies are needed to confirm our findings. Clinical Rehabilitation Impact: The combination of guided mindfulness and physical activity shows promise as a treatment modality in rehabilitation of impaired information processing speed and mental fatigue following ABI.
\end{abstract}

\section{Keywords}

Rehabilitation, Acquired Brain Injury, Mental Fatigue, Cognition 


\section{Introduction}

Two of the most common cognitive consequences of acquired brain injury (ABI) are impaired working memory and impaired information processing speed [1] [2], both of which have been found to have a negative impact on everyday life [3] [4]. In addition, people with impaired information processing speed may complain of emotional effects linked to the slowness, such as irritability, a tendency to feel stressed (feelings of time pressure and panic) and fatigue [4]. Mental fatigue is also common in the aftermath of ABI [5] and has been shown to affect quality of life and functioning negatively in everyday life [6]. There is, to our knowledge, very limited knowledge concerning the effects of a combination of mindfulness and physical activity in patients with $\mathrm{ABI}$.

In addition, persons with $\mathrm{ABI}$, taken as a group, have lower levels of aerobic capacity compared with the normal population [7] [8]. This increases the risk of cardiovascular diseases [9] and might also negatively affect already impaired cognitive function [10]. Thus, finding ways to reduce cognitive impairments, improve aerobic capacity and ameliorate the negative impact on everyday life is an important focus of research. During the past decade, several new targets for research on rehabilitation of cognition and mental fatigue have been suggested, including mindfulness [11] and physical activity [12] [13].

Mindfulness can be defined as skills that aim to direct ones attention to the present moment experience-and adopting an attitude of acceptance regarding that experience [14]. It has been suggested that mindfulness could reduce mental fatigue in persons with $\mathrm{ABI}$ [15] and improve cognition, e.g. information processing speed [15] [16] as well as working memory [16]. In addition, there is some evidence that physical activity is beneficial for cognitive functions [17], e.g. information processing [13], and mental fatigue [18], in persons with ABI.

Thus, there is some evidence that mindfulness and physical activity separately has a beneficial effect on cognition, but there is very limited knowledge concerning the effects of a combination of mindfulness and physical activity in patients with ABI.

The aim of this pilot study was to analyse effects of a combination of guided mindfulness and aerobic exercise on cognitive ability and mental fatigue in patients with $\mathrm{ABI}$.

\section{Methods}

\subsection{Subjects}

The inclusion criteria were: a diagnosed non-progressive ABI; age $>18$ years; $>6$ months after occurrence of brain lesion; a subjective reported cognitive impairment; a cognitive status equivalent to Rancho Los Amigo Scale [19] level VII-X, an expected ability to walk for at least 40 minutes and being regarded as motivated for training.

Exclusion criteria were: aphasia; neuropsychiatric diagnoses; depression as clinically assessed by a neuropsychologist; simultaneous participation in any 
other type of organized cognitive training.

Sample size was determined based on a power analysis on a former study on patients with $\mathrm{ABI}$ who participated in another rehabilitation intervention (working memory training) were partly the same neuropsychological tests were used [20]. The participants of the present study had been patients at any of three rehabilitation medicine departments in Sweden. Persons eligible for inclusion were identified by staff members through a search of medical records dating from June 2013 to June 2015 according to inclusion and exclusion criteria. The staff members identified 59 eligible persons (without any other ongoing rehabilitation intervention) who were sent an information letter with an invitation to participate in the study. Twenty-six persons chose to participate and provided informed consent. The remaining persons declined due to lack of time or did not reply. Five participants were excluded during the intervention; four did not complete the training because of lack of time or medical interventions unrelated to the brain injury and one participant developed neuropathic pain (unrelated to training).

\subsection{The Intervention}

The intervention comprised a structured combination of mindfulness and outdoor walking in a forest or pathway with surrounding trees in proximity to each of the respective rehabilitation departments, three times/week for 12 weeks. Each session started with walking, 10 minutes at exertion level 11 (Borgs Rating of Perceived Exertion-light) [21] followed by 30 minutes walking or jogging at exertion level 13 (Borgs Rating of Perceived Exertion-somewhat hard). During the first 10 minutes, the participants were allowed to talk to each other, while for the remaining 30 minutes they walked silently focusing on the surrounding nature. The outdoor session was followed by mindfulness training indoors, inspired by mindfulness-based stress reduction [22], including body scanning, breathing and yoga. After each session, the participants had a discussion based on their experience of the session, including implications for everyday life. The sessions were based on a manual and led by three physiotherapists, one from each rehabilitation department, qualified as mindfulness instructors. In addition to these sessions, the participants did mindfulness training for 30 minutes at home, three times/week. The homework was assisted by a training guide, a training diary and an audio file. Thus, the intervention comprised a total of 24 organized aerobic exercise sessions and up to 72 mindfulness exercise sessions (including the sessions performed at home).

\subsection{Outcomes}

The outcome measures comprised cognitive assessment tests for evaluation of information processing speed and working memory, an ergometer test and self-reported mental fatigue. Two neuropsychologists, who were not engaged in any part of the intervention, did the cognitive assessments before and after 12 
weeks training. The tests were administered in the same order and in the same way for each participant at every assessment occasion. One physiotherapist did all the ergometer tests before and after 12 weeks of training.

\subsubsection{Test of Oxygen Uptake}

The Åstrand test is a submaximal evaluation of oxygen uptake [23]. The participants were asked to pedal on a cycle ergometer for approximately $6-10$ minutes with a constant workload, while having the heartrate measured every minute. The steady state heart rate was looked up in a published table to determine the estimated maximal oxygen uptake $\left(\mathrm{V}_{\mathrm{O}_{2}} \max\right.$. ).

\subsubsection{Neuropsychological Testing}

Neuropsychological tests were selected to cover aspects of information processing speed, attention and working memory, cognitive functions often impaired in the brain injured population [1] [2] and found to be affected by physical activity or mindfulness [13] [15] [16]:

Paced Auditory Serial Attention Test 2.4 (PASAT) [24]. The task in PASAT involves a long series of digits read out over a short interval, and the participants' task is to add the digit they just heard to the preceding one.

Block repetition, forward and backward, from WMS-III [25]. The test contains ten cubes that are spread irregularly on a rectangular surface. The test leader points to the cubes/blocks in a certain order and the participants' task is to point to the blocks in the same order (forward block repetition) and in reverse order (backward block repetition). The number of blocks that the test leader points to in a set varies between two and eight blocks.

Listening span task [26]. Sentences with three words are presented in groups of three to six sentences. The task is to answer yes or no depending on whether the sentence is meaningful or nonsense. Then, participants have to repeat the first or last word, not knowing which in advance.

Digit Symbol Coding (DSC) from WAIS-IV [27] consists of copying symbols paired with numbers in a limited time.

Trail Making Test (TMT) from D-KEFS [28]. The first part of TMT is a visual scanning task, and parts II-IV consist of a series of connect-the-circle tasks, part II in numerical order, part III in alphabetical order and part IV alternating numbers and letters.

DLS reading speed test (DLS) [29]. The task is to read a text silently and, as a way to check reading comprehension, mark the correct word among three in parentheses spread evenly in the text.

\subsubsection{Self-Estimated Mental Fatigue}

The participants filled in Mental Fatigue Scale (MFS) [30] before and after 12 weeks of training. MFS includes 15 questions. The rating focuses on intensity, frequency and duration of common symptoms associated with mental fatigue after brain injury. 


\subsection{Statistics}

Data were analyzed using IBM SPSS Statistics 21. Descriptive results from the assessments were presented as the median and IQR. To compare differences in the results before and after the intervention, non-parametric statistics (Wilcoxon matched-pair signed ranks test) was used because of the limited number of participants and a skewed distribution of data. Effect size for each analysis was calculated using Rosenthal's r. For correlation analyses, Spearman's rank correlation test was used. The accepted level of significance was $\mathrm{p}<0.05$.

\subsection{Ethical Considerations}

No medical or other risks related to participation in the study could be identified. Written informed consent was obtained from the participants before the study. The study was approved by the local research ethics committee (2015/168-319).

\section{Results}

\subsection{Background Data}

This study included 21 participants with ABI. Characteristics of the participants, such as gender and diagnoses, is described in Table 1 . The median age was 61 years (interquartile range [IQR], 49.5 - 66 years) and median time since injury was 14 months (IQR, 11 - 46.5 months).

\subsection{Oxygen Uptake}

As the aim of the study was to look at potential positive cognitive effects from physical training, it was important to check how physical capacity did change with intervention. Before the intervention, the median oxygen uptake expressed as $\mathrm{ml}$ of $\mathrm{O}_{2}$ per $\mathrm{kg}$ body weight per minute was $28.0 \mathrm{ml}$ (IQR, $23.0-35.0 \mathrm{ml}$ ); at follow-up, the median was $35.0 \mathrm{ml}$ (IQR, $28.0-45.0 \mathrm{ml}, \mathrm{p}<0.001$ ), indicating that the intervention had had a positive effect on aerobic capacity.

\subsection{Neuropsychological Tests}

Results of the neuropsychological tests TMT I-IV, DLS and DSC showed an

Table 1. Diagnoses and gender of the participants

\begin{tabular}{|c|c|c|c|}
\hline & & $\mathbf{n}$ & $\%$ \\
\hline \multicolumn{4}{|c|}{ Diagnoses } \\
\hline & Stroke & 9 & 43 \\
\hline & Traumatic brain injury & 6 & 29 \\
\hline & Encephalitis/Meningitis & 4 & 19 \\
\hline & Other & 2 & 9 \\
\hline \multicolumn{4}{|l|}{ Gender } \\
\hline & Men & 9 & 43 \\
\hline & Women & 12 & 57 \\
\hline
\end{tabular}


Table 2. Diagnoses and gender of the Results from the neuropsychological tests before the intervention and at follow-up after the intervention participants.

\begin{tabular}{ccccc}
\hline & $\begin{array}{c}\text { Before } \\
\text { median (IQR) }\end{array}$ & $\begin{array}{c}\text { After } \\
\text { median, (IQR) }\end{array}$ & Effect size & $p$ value \\
\hline TMT I (seconds) & $28(23.5-33.5)$ & $23(18.5-28)$ & 0.49 & 0.001 \\
TMT II (seconds) & $39(34.5-58.5)$ & $36(28.5-45)$ & 0.35 & 0.022 \\
TMT III (seconds) & $38(33.5-58.5)$ & $33(24.5-48.5)$ & 0.43 & 0.005 \\
TMT IV (seconds) & $103(85.5-139)$ & $84(68-112.5)$ & 0.32 & 0.035 \\
DLS (number of words) & $17(14-21.5)$ & $21(17.5-29.5)$ & 0.43 & 0.006 \\
DSC (number of symbols) & $49(41-59)$ & $54(49-65)$ & 0.43 & 0.006 \\
PASAT (number of words) & $35(28-45)$ & $40(31-49)$ & 0.29 & 0.077 , n.s. \\
Block repetition (number of blocks) & $13(11-16)$ & $14(12-16)$ & 0.15 & 0.324 , n.s. \\
Listening span (number of words) & $26(19-28)$ & $25(19-30)$ & 0.15 & 0.340 , n.s. \\
\hline
\end{tabular}

Wilcoxon matched pairs test was used for comparison between results from before the intervention versus after 12 weeks of intervention. Effects sizes was calculated using Rosenthal's $r$. TMT I-IV: Trail Making Test parts I-IV. DLS: DLS reading speed test. DSC: Digit Symbol Coding. PASAT: Paced Auditory Serial Attention Test.

Table 3. Diagnoses and gender of the Results from the neuropsychological tests before the intervention and at follow-up after the intervention participants.

\begin{tabular}{ccccc}
\hline & $\begin{array}{c}\text { Before } \\
\text { median (IQR) }\end{array}$ & $\begin{array}{c}\text { After } \\
\text { median, (IQR) }\end{array}$ & Effect size & p value \\
\hline MFS & $15.0(9.8-19.0)$ & $13.0(8.8-18.0)$ & 0.32 & 0.040 \\
\hline
\end{tabular}

Wilcoxon matched pairs test was used for comparison between results from before the intervention versus after 12 weeks of intervention. Effects sizes was calculated using Rosenthals $r$. MFS: Mental Fatigue Scale.

improvement after intervention (Table 2). Whereas the results of PASAT, Block repetition and Listening span, did not show any improvement (Table 2).

\subsection{Self-Estimated Mental Fatigue}

Perceived mental fatigue, as measured by MFS, was significantly reduced (Table 3).

\subsection{Correlations}

To investigate if the changes in those neuropsychological test with significant results after training were correlated to the change in perceived mental fatigue, correlation analyses were made using the differences in results between pre- and post-test results. Significant correlations were found between the difference in patients' perceived mental fatigue and the difference in DSC $(r=0.549, \mathrm{p}<0.05)$ and TMT-IV $(\mathrm{r}=0.479, \mathrm{p}<0.05)$ respectively.

\section{Discussion}

The aim of this pilot study was to analyse the effects of an intervention including guided mindfulness sessions combined with aerobic exercise on cognitive ability 
and mental fatigue. The results showed improvements in MFS, as well as the neuropsychological tests TMTI-IV, DLS and DSC. DSC is part of the processing speed index in WAIS, and as such it is commonly used to assess information processing speed [27]. DLS represent a somewhat more complex task than DSC, and as it has been shown to correlate with DSC [31], it can be seen as a way to use a common everyday task related to information processing speed in the assessment. DSC and DLS both have been used in previous research of mental fatigue as tests focusing on speed [31]. TMT I-III are meant to measure visual scanning, number and letter sequencing respectively [28], but as the tasks are less complex and measurements include how fast the task is completed, the results of these subtests are probably reflecting some aspect of information processing speed. On the other hand, TMT-IV, which is more complex, is one of many known versions of TMT-tests, that have shown a correlation with tests measuring information processing speed but also with attention and cognitive flexibility [32]. The results didn't show any improvement in the well-known neuropsychological tests of verbal and visual working memory; PASAT, Block repetition and Listening span, that previously have been used in research focusing on rehabilitation of impaired working memory [20]. The results imply that the intervention did have a positive effect on cognitive abilities mainly related to information processing speed and on perceived mental fatigue, but not on cognitive abilities more related to working memory.

Information processing speed and working memory are related [33] and thus difficult to fully separate. The current working memory tests used in this study require combined working memory functions of temporary storage, processing as well as executive attention. As working memory demands temporary storage of information as well as manipulation of that information [34], it can be seen as a cognitive function that requires sequential (possibly partially simultaneous) processing. According to theories of the relation between information processing speed and cognition, such as "limited time mechanism" and "simultaneity mechanism", slow information processing speed might lead to ineffective processing of cognitive functions that require sequential processing, such as working memory [35]. Further, it has been hypothesized that there is a cognitive developmental cascade during childhood where an increase in speed precedes an increase in working memory [33] and that decreasing information processing speed during old age at least partly accounts for an associated working memory decline [35]. Thus, an improvement of information processing speed following the intervention in the present study would have been expected to lead to some improvement of working memory, but the results didn't show that. However, working memory is a cognitively more demanding process than information processing speed [36], and might therefore be more difficult to influence. And, because of the composite nature of working memory, it is probably more related to complex cognitive tasks in daily living and working activities than more simple information processing functions.

Kohl et al. [37], found increased activity in the brain when patients with brain 
injury performed an activity requiring information processing speed compared with healthy controls. Based on findings such as this, it has been hypothesized that mental activity demands a greater effort for the injured brain. This hypothesis is called the "coping hypothesis" as it explains the mental fatigue as related to increased mental effort caused by slow processing and attention deficit; thus "the brain needs to work harder" [5]. The association between slow information processing and mental fatigue is also implied in the complaints made by individuals with impaired information processing speed of fatigue and associated symptoms, such as increased emotionality and irritability, headaches and sensitivity to stress [4]. The link between mental fatigue and slow information processing speed, which could be seen as part of the coping hypothesis, indicates that to find a treatment for these patients, we need to find a way to affect both symptoms. The combination of mindfulness and aerobic exercise after ABI might be one way to achieve this, since results showed a positive effect on mental fatigue as well as on tests related to information processing speed. It is important to understand the processes targeted by the intervention program for understanding and evaluating why transfer to certain functions occur. Since impaired information processing speed and mental fatigue are common symptoms after ABI [2] [5], that makes it harder to recover functionally [6] [38] and have a normal social and occupational functioning [6] [38], this is of significant clinical interest.

Perceived results might be secondary to reduced stress, which should be further studied. Previous research on healthy individuals has shown that mindfulness can affect neural networks considered important in activation of stress [39]. Ziino et al. [40] showed that, after ABI, patients with mental fatigue could compensate for the increased cognitive strain for a while, but it was still effortful as shown in increased stress levels. Thus, mindfulness might help patients with mental fatigue to deal with stress due to the increased effort needed (to compensate for impaired information processing speed and attention [5]) in the cognitive demands of everyday living.

If mindfulness affects the neural networks also after a brain injury, then one of the benefits of adding aerobic exercise might be to facilitate this effect, as aerobic exercise has been shown to enhance neuroplasticity [41]. Furthermore, the aerobic exercise might affect stress levels more directly, e.g. it has been shown to lead to reduced stress responses [42]. Hence, the reduced mental fatigue and improved information processing speed might be due to the stress-buffering effect of the aerobic exercise.

Kaplan proposed a model where information processing, stress and (attentional) fatigue were related to each other [43]. For example, his model shows that cognitive resource inadequacy can lead to a stress response and an impaired performance in cognitively demanding tasks. In addition, a stress response can lead to a faster resource decline, which in turn leads to an impaired performance [43]. Kaplan's model might be of help in understanding the effect of mindfulness and physical activity on information processing speed and mental fatigue in patients with $\mathrm{ABI}$ as secondary to an effect on stress. 
Well-established, valid and reliable outcome measurements were chosen for this study to optimize the quality and trustworthiness. Further strengths of the study were that all assessments were performed by two neuropsychologists and one physiotherapist, all with long experience of assessments following ABI and who were not engaged in the intervention. To assure that the intervention was equivalent in all three locations, it was based on a manual and led by three physiotherapists with the same education in mindfulness.

This study was a pilot study and therefore the sample is small, it is intended to serve as a basis for further studies with larger sample sizes to confirm the results and discussion on the underlying factors in relation to results. Larger sample sizes are also a necessity to be able to form a control group. Another reason to conduct a pilot study is to test feasibility of the intervention. The compliance to the intervention was very good. Despite the relatively intense program, the participants did not complain of fatigue due to the activity; on the contrary, perceived mental fatigue was found to be reduced and the participants expressed that they intended to continue the exercises after the 12 weeks.

Because functional recovery has been shown to be mostly completed after approximately 3 months [44], we chose to include patients at least 6 months after their injury to minimize the risk of effects caused by spontaneous recovery. Furthermore, the median time since injury was 14 months, when further recovery of mental fatigue is no longer expected [45]. A confounding factor is possible influence by a test-retest effect. Because this study did not have a control group, it is not possible to refute this. However, other studies with a control group imply that our results are probably not due to test-retest effects [20] [46].

\section{Conclusions}

Impaired information processing speed and mental fatigue are common following $\mathrm{ABI}$ [2] [5], and has been shown to have a negative impact on everyday life [4] [6]. Therefore, it is important to address these problems in rehabilitation. The coping hypothesis, which links slow information processing and mental fatigue, indicates that we need to affect both symptoms to achieve successful rehabilitation. Although we seem to be far from finding a way to "cure" mental fatigue and restore impaired information processing speed, we suggest that mindfulness and physical activity, such as walking at an exertion level of "somewhat hard", is a possible way to influence both symptoms somewhat.

Since the combination of mindfulness and aerobic exercise (with the potential addition of nature) seems to increase information processing speed and ameliorate mental fatigue, this raises the question of why this is so. How can we understand the possible underlying mechanism? A hypothesis from this study is that the effect of the intervention on information processing speed and mental fatigue is secondary to an effect on stress. Further studies are needed to confirm presented results and to test this hypothesis. 


\section{Acknowledgements}

The authors would like to thank the participants of the intervention. The authors would also like to thank the neuropsychologist Kit Schwerdt and occupational therapist Margareta Fridén for data collection, and the physiotherapists who led the intervention; Eva Lilliecreutz, Beatrice Felixson and Caroline Leon. The study was supported financially by Futurum, Academy for Health and Care (grant numbers Futurum-519331, Futurum-608761) and the Medical Research Council of Southeast Sweden (grant number FORSS-559471).

\section{Conflicts of Interest}

The authors have no conflicts of interest to disclose.

\section{References}

[1] Schaapsmeerders, P., Maaijwee, N.A., van Dijk, E.J., Rutten-Jacobs, L.C., Arntz, R.M., Schoonderwaldt, H.C., Dorresteijn, L.D., Kessels, R.P. and de Leeuw, F.E. (2013) Long-Term Cognitive Impairment after First-Ever Ischemic Stroke in Young Adults. Stroke, 44, 1621-1628. https://doi.org/10.1161/STROKEAHA.111.000792

[2] Hochstenbach, J., Mulder, T., van Limbeek, J., Donders, R. and Schoonderwaldt, H. (1998) Cognitive Decline Following Stroke: A Comprehensive Study of Cognitive Decline Following Stroke. Journal of Clinical and Experimental Neuropsychology, 20, 503-517. https://doi.org/10.1076/jcen.20.4.503.1471

[3] Vallat-Azouvi, C., Pradat-Diehl, P. and Azouvi, P. (2012) The Working Memory Questionnaire: A Scale to Assess Everyday Life Problems Related to Deficits of Working Memory in Brain Injured Patients. Neuropsycholical Rehabilitation, 22, 634-649. https://doi.org/10.1080/09602011.2012.681110

[4] Winkens, I., Van Heugten, C.M., Fasotti, L., Duits, A.A. and Wade, D.T. (2006) Manifestations of Mental Slowness in the Daily Life of Patients with Stroke: A Qualitative Study. Clinival Rehabilitation, 20, 827-834.

https://doi.org/10.1177/0269215506070813

[5] Belmont, A., Agar, N., Hugeron, C., Gallais, B. and Azouvi, P. (2006) Fatigue and Traumatic Brain Injury. Annales de Readaptation et de Medecine Physique, 49, 283-288, 370-284. https://doi.org/10.1016/j.annrmp.2006.04.018

[6] Cantor, J.B., Ashman, T., Gordon, W., Ginsberg, A., Engmann, C., Egan, M., Spielman, L., Dijkers, M. and Flanagan, S. (2008) Fatigue after Traumatic Brain Injury and Its Impact on Participation and Quality of Life. The Journal of Head Trauma Rehabilitation, 23, 41-51. https://doi.org/10.1097/01.HTR.0000308720.70288.af

[7] Hassett, L., Moseley, A. and Harmer, A. (2016) The Aetiology of Reduced Cardiorespiratory Fitness among Adults with Severe Traumatic Brain Injury and the Relationship with Physical Activity: A Narrative Review. Brain Impairment, 17, 43-54. https://doi.org/10.1017/BrImp.2015.28

[8] Mackay-Lyons, M.J. and Makrides, L. (2004) Longitudinal Changes in Exercise Capacity after Stroke. Archives of Physical Medicine and Rehabilitation, 85, 1608 1612. https://doi.org/10.1016/j.apmr.2004.01.027

[9] Williams, P.T. (2001) Physical Fitness and Activity as Separate Heart Disease Risk Factors: A Meta-Analysis. Medicine \& Science in Sports \& Exercise, 33, 754-761. https://doi.org/10.1097/00005768-200105000-00012

[10] Barnes, D.E., Yaffe, K., Satariano, W.A. and Tager, I.B. (2003) A Longitudinal Study 
of Cardiorespiratory Fitness and Cognitive Function in Healthy Older Adults. Journal of the American Geriatrics Society, 51, 459-465. https://doi.org/10.1046/j.1532-5415.2003.51153.x

[11] Johansson, B.R.L. (2012) Mental Fatigue; A Common Long Term Consequence after a Brain Injury. Brain Injury-Functional Aspects, Rehabilitation an Prevention. A. Agrawal, In Tech. https://doi.org/10.5772/27042

[12] Duncan, F., Lewis, S.J., Greig, C.A., Dennis, M.S., Sharpe, M., MacLullich, A.M. and Mead, G.E. (2015) Exploratory Longitudinal Cohort Study of Associations of Fatigue after Stroke. Stroke, 46, 1052-1058. https://doi.org/10.1161/STROKEAHA.114.008079

[13] Chin, L.M., Keyser, R.E., Dsurney, J. and Chan, L. (2015) Improved Cognitive Performance Following Aerobic Exercise Training in People with Traumatic Brain Injury. Archives of Physical Medicine and Rehabilitation, 96, 754-759. https://doi.org/10.1016/j.apmr.2014.11.009

[14] Creswell, J.D. (2017) Mindfulness Interventions. Annual Review of Psychology, 68, 491-516. https://doi.org/10.1146/annurev-psych-042716-051139

[15] Johansson, B., Bjurh, H., Karlsson, M., Karlsson, J-O. and Rönnbäck, L. (2015) Mindfulness-Based Stress Reduction (MBSR) Delivered Live on the Internet to Individuals Suffering from Mental Fatigue after an Acquired Brain Injury. Mindfulness, 6, 1356-1365. https://doi.org/10.1007/s12671-015-0406-7

[16] Azulay, J., Smart, C.M., Mott, T. and Cicerone, K.D. (2013) A Pilot Study Examining the Effect of Mindfulness-Based Stress Reduction on Symptoms of Chronic Mild Traumatic Brain Injury/Postconcussive Syndrome. Journal of Head Trauma Rehabilitation, 28, 323-331. https://doi.org/10.1097/HTR.0b013e318250ebda

[17] Cumming, T.B., Tyedin, K., Churilov, L., Morris, M.E. and Bernhardt, J. (2012) The Effect of Physical Activity on Cognitive Function after Stroke: A Systematic Review. International Psychogeriatrics, 24, 557-567.

[18] Kolakowsky-Hayner, S.A., Bellon, K., Toda, K., Bushnik, T., Wright, J., Isaac, L. and Englander, J. (2017) A Randomised Control Trial of Walking to Ameliorate Brain Injury Fatigue: A NIDRR TBI Model System Centre-Based Study. Neuropsychological Rehabilitation, 27, 1002-1018. https://doi.org/10.1080/09602011.2016.1229680

[19] Hagen, C. and Durham, P. (1987) Levels of Cognitive Functioning, in Rehabilitation of the Head Injured Adult: Comprehensive Physical Management Professional Staff Association of Rancho Los Amigos Hospital. Rancho Los Amigos Hospital, Downey.

[20] Lundqvist, A., Grundstrom, K., Samuelsson, K. and Ronnberg, J. (2010) Computerized Training of Working Memory in a Group of Patients Suffering from Acquired Brain Injury. Brain Injury, 24, 1173-1183.

https://doi.org/10.3109/02699052.2010.498007

[21] Borg, G.A. (1974) Perceived Exertion. Exercise and Sport Sciences Reviews, 2, 131 153. https://doi.org/10.1249/00003677-197400020-00006

[22] Kabat-Zinn, J.L. and Burney, R. (1985) The Clinical Use of Mindfulness Meditation for the Self-Regulation of Chronic Pain. Journal of Behavioral Medicine, 8, 163-190. https://doi.org/10.1007/BF00845519

[23] Åstrand, P.-O. and Ryhming, I. (1954) A Nomogram for Calculation of Aerobic Capacity (Physical Fitness) from Pulse Rate during Submaximal Work. Journal of Applied Physiology, 7, 218-221. https://doi.org/10.1152/jappl.1954.7.2.218

[24] Gronwall, D.M. (1977) Paced Auditory Serial-Addition Task: A Measure of Recovery from Concussion. Perceptual and Motor Skills, 44, 367-373. 
https://doi.org/10.2466/pms.1977.44.2.367

[25] Tulsky, D., Chiaravalloti, N., Palmer, B.W. and Chelune, G. (2003) The Wechsler Memory Scale. 3rd Edition.

[26] Conway, A.R., Kane, M.J., Bunting, M.F., Hambrick, D.Z., Wilhelm, O. and Engle, R.W. (2005) Working Memory Span Tasks: A Methodological Review and User's Guide. Psychonomic Bulletin \& Review, 12, 769-786. https://doi.org/10.3758/BF03196772

[27] Wechsler, D. (2008) Wechsler Adult Intelligence Scale: WAIS-IV; Technical and Interpretive Manual. Pearson, London.

[28] Delis, D.C., Kaplan, E. and Kramer, J.H. (2001) Delis Kaplan Executive Function System, D-KEFS. San Antonio, Harcourt Assessment.

[29] Järpsten, B. (2002) DLS handledning för skolår 7-9 och år 1 i gymnasiet. Stockholm, Hogrefe.

[30] Johansson, B., Starmark, A., Berglund, P., Rodholm, M. and Ronnback, L. (2010) A Self-Assessment Questionnaire for Mental Fatigue and Related Symptoms after Neurological Disorders and Injuries. Brain Injury, 24, 2-12. https://doi.org/10.3109/02699050903452961

[31] Johansson, B., Berglund, P. and Ronnback, L. (2009) Mental Fatigue and Impaired Information Processing after Mild and Moderate Traumatic Brain Injury. Brain Injury, 23, 1027-1040. https://doi.org/10.3109/02699050903421099

[32] Strauss, E., Sherman, E.M. and Spreen, O. (2006) A Compendium of Neuropsychological Tests: Administration, Norms, and Commentary. American Chemical Society.

[33] Fry, A.F. and Hale, S. (2000) Relationships among Processing Speed, Working Memory, and Fluid Intelligence in Children. Biological Psychology, 54, 1-34. https://doi.org/10.1016/S0301-0511(00)00051-X

[34] Baddeley, A. (2012) Working Memory: Theories, Models, and Controversies. Annual Review of Psychology, 63, 1-29. https://doi.org/10.1146/annurev-psych-120710-100422

[35] Salthouse, T.A. (1996) The Processing-Speed Theory of Adult Age Differences in Cognition. Psychological Review, 103, 403-428. https://doi.org/10.1037/0033-295X.103.3.403

[36] Luciano, M., Wright, M., Smith, G., Geffen, G., Geffen, L. and Martin, N. (2001) Genetic Covariance among Measures of Information Processing Speed, Working Memory, and IQ. Behavior Genetics, 31, 581-592. https://doi.org/10.1023/A:1013397428612

[37] Kohl, A.D., Wylie, G.R., Genova, H.M., Hillary, F.G. and Deluca, J. (2009) The Neural Correlates of Cognitive Fatigue in Traumatic Brain Injury Using Functional MRI. Brain Injury, 23, 420-432. https://doi.org/10.1080/02699050902788519

[38] Rassovsky, Y., Satz, P., Alfano, M.S., Light, R.K., Zaucha, K., McArthur, D.L. and Hovda, D. (2006) Functional Outcome in TBI II: Verbal Memory and Information Processing Speed Mediators. Journal of Clinical and Experimental Neuropsycholo$g y$, 28, 581-591. https://doi.org/10.1080/13803390500434474

[39] Taren, A.A., Creswell, J.D. and Gianaros, P.J. (2013) Dispositional Mindfulness Co-Varies with Smaller Amygdala and Caudate Volumes in Community Adults. PLOS ONE, 8, e64574. https://doi.org/10.1371/journal.pone.0064574

[40] Ziino, C. and Ponsford, J. (2006) Vigilance and Fatigue Following Traumatic Brain Injury. Journal of the International Neuropsychological Society, 12, 100-110. 
https://doi.org/10.1017/S1355617706060139

[41] Kempermann, G., Fabel, K., Ehninger, D., Babu, H., Leal-Galicia, P., Garthe, A. and Wolf, S.A. (2010) Why and How Physical Activity Promotes Experience-Induced Brain Plasticity. Frontiers in Neuroscience, 4, 189.

https://doi.org/10.3389/fnins.2010.00189

[42] Zschucke, E., Renneberg, B., Dimeo, F., Wüstenberg, T. and Ströhle, A. (2015) The Stress-Buffering Effect of Acute Exercise: Evidence for HPA Axis Negative Feedback. Psychoneuroendocrinology, 51, 414-425.

https://doi.org/10.1016/j.psyneuen.2014.10.019

[43] Kaplan, S. (1995) The Restorative Benefits of Nature: Toward an Integrative Framework. Journal of Environmental Psychology, 15, 169-182.

https://doi.org/10.1016/0272-4944(95)90001-2

[44] Jørgensen, H.S., Nakayama, H., Raaschou, H.O., Vive-Larsen, J., Støier, M. and Olsen, T.S. (1995) Outcome and Time Course of Recovery in Stroke. Part II: Time Course of Recovery. The Copenhagen Stroke Study. Archives of Physical Medicine and Rehabilitation, 76, 406-412. https://doi.org/10.1016/S0003-9993(95)80568-0

[45] Bushnik, T., Englander, J. and Wright, J. (2008) Patterns of Fatigue and Its Correlates over the First 2 Years after Traumatic Brain Injury. Journal of Head Trauma Rehabilitation, 23, 25-32. https://doi.org/10.1097/01.HTR.0000308718.88214.bb

[46] Johansson, B., Bjuhr, H. and Ronnback, L. (2012) Mindfulness-Based Stress Reduction (MBSR) Improves Long-Term Mental Fatigue after Stroke or Traumatic Brain Injury. Brain Injury, 26, 1621-1628. https://doi.org/10.3109/02699052.2012.700082 